\title{
Biology of urothelial tumorigenesis: insights from genetically engineered mice
}

\author{
Xue-Ru Wu
}

Published online: 11 December 2009

(C) The Author(s) 2009. This article is published with open access at Springerlink.com

\begin{abstract}
Urothelium, one of the slowest cycling epithelia in the body, embodies a unique biological context for cellular transformation. Introduction of oncogenes into or removing tumor suppressor genes from the urothelial cells or a combination of both using the transgenic and/or knockout mouse approaches has provided useful insights into the molecular mechanisms of urothelial transformation and tumorigenesis. It is becoming increasingly clear that overactivation of the receptor tyrosine kinase (RTK) pathway, as exemplified by the constitutively activated Ha-ras oncogene, is both necessary and sufficient to initiate the low-grade, non-invasive urothelial carcinomas. Dosage of the mutated Ha-ras, but not concurrent inactivation of pro-senescence molecules p16Ink4a and p19Arf, dictates whether and when the low-grade urothelial carcinomas arise. Inactivation of both $\mathrm{p} 53$ and $\mathrm{pRb}$, a prevailing paradigm previously proposed for muscle-invasive urothelial tumorigenesis, is found to be necessary but insufficient to initiate this urothelial carcinoma variant. Instead, downregulation in p53/pRb co-deficient urothelial cells of p107, a pRb family member, is associated with the genesis of the muscleinvasive bladder cancers. p53 deficiency also seems to be capable of cooperating with that of PTEN in eliciting invasive urothelial carcinomas. The genetically engineered mice have improved the molecular definition of the divergent
\end{abstract}

\footnotetext{
X.-R. Wu

Departments of Urology and Pathology,

New York University School of Medicine,

New York, NY 10016, USA

X.-R. Wu $(\triangle)$

Veterans Affairs New York Harbor Healthcare System,

Manhattan Campus,

423 E23 Street, Room 18064S,

New York, NY 10010, USA

e-mail: xue-ru.wu@med.nyu.edu
}

pathways of urothelial tumorigenesis and progression, helped delineate the intricate crosstalk among different genetic alterations within a urothelium-specific context, identified new prognostic markers and novel therapeutic targets potentially applicable for clinical intervention, and provided in vivo platforms for testing preventive strategies of bladder cancer.

Keywords Bladder cancer. Urothelium - Cellular context . Tumorigenesis $\cdot$ Transgenic $\cdot$ Knockout

\section{Introduction}

Tumors are a phenotypic manifestation of genomic, genetic, and epigenetic abnormalities [1-3]. While few tissues can escape tumorigenesis, the vulnerability of different tissues to a given oncogenic alteration or several well-defined oncogenic alterations varies considerably. Evidence is mounting that this divergent vulnerability, generally referred to as tissue-specificity or cellular context-dependency of tumorigenesis, is more of a rule than an exception [4]. At the heart of this concept is the critical contribution of intrinsic biological properties of an affected tissue to oncogenic processes. Compelling evidence exists, from both human patients and animal models, supporting the cell-typedependent tumorigenicity by a range of oncogenic alterations. For instance, germline mutations of adenomatosis polyposis coli (APC) gene in humans affect primarily the colorectal epithelial cells, predisposing them to adenoma formation [5-7]. Patients with germline mutations in von Hippel-Lindau (VHL) gene are particularly prone to developing early-onset renal cell carcinomas [8, 9]. Germline mutations of p53 gene, which cause Li-Fraumeni syndrome, preferentially transform soft tissues and mammary gland into 
malignancies [10, 11]. Patients with Costello syndrome, which is caused by germline mutations in the Ha-ras oncogene, are highly susceptible to tumor development in skeletal muscle and bladder urothelial cells $[12,13]$. This type of tissue-selectivity in tumor susceptibility has been reproduced in genetically engineered animals as well. Thus, global inactivation of p53 gene in mice leads to a high incidence of thymic lymphomas and soft tissue sarcomas while sparing most other tissues from early-onset tumorigenesis [14]. Transgenic expression of the same oncogene or conditional abrogation of the same tumor suppressor gene in different tissues under the control of tissue-specific promoters also frequently results in significant variations in tumor initiating ability, phenotype, latency, and penetrance [15-18]. These and many other examples are strongly indicative of the fundamental role that the cellular context plays in influencing whether and when tumorigenesis takes places under a well-defined genetic circumstance.

Precisely why different tissues respond to oncogenic assaults drastically differently remains poorly understood. While still evolving, the phenomenon may be a result of an intricate interplay of multiple intrinsic factors within a given tissue. These may include, but not necessarily be limited to, the steady-state proliferation rate of a tissue, the mode of baseline signal wiring, the microenvironment, the accessibility to growth factors and the level of growth factor receptor expression, the ability (or the lack thereof) to mount an effective tumor defense against genotoxins via senescence, apoptosis, and DNA damage response, the balance and collaborative arrangements between growth promoters and inhibitors, and so on. In this review, I will focus on the biological aspects of urothelial tumorigenesis based primarily on recent data obtained from transgenic and knockout mouse models, with reference to human bladder cancer whenever appropriate. Information learned from xenograft and orthotopic bladder cancers and chemical carcinogenesis models will not be discussed here and readers are referred to several reviews published previously [19-21].

\section{Unique context of urothelium in tumorigenesis}

Urothelium, from which all the urothelial tumors originate, is a highly specialized epithelium [22-24]. Situated strategically between the urine and blood, normal urothelium acts as a physiologically effective and mechanically flexible permeability barrier that on the one hand protects the underlying tissues from toxic urinary substances and on the other hand adjusts its surface area actively and reversibly during the micturition cycle $[25,26]$. To satisfy the requirement for stability, urothelium cycles extremely slowly, with a turnover rate of about 200 days and a tritiumthymidine labeling index of less than $0.01 \%[27,28]$.
Histologically a stratified and polarized epithelium, urothelium is comprised of a single-cell type with phenotypic differences between different cell layers attributed to the different degree of cellular differentiation. Cells in the basal layer are the smallest in size and least differentiated, and this is where the proliferative compartment and stem cells are believed to reside [29]. While the basal layer is the only urothelial layer that expresses an appreciable level of epidermal growth factor (EGF) receptor [30, 31], this layer is inaccessible to the exceedingly high concentration of EGF in the urine, due to the barrier provided by the superficial urothelial layer [32]. Similarly, urothelial basal cells are normally well protected from an assortment of urinary carcinogens. The basal cells can differentiate to become intermediate cells whose layer thickness depends on the species (one layer in rodents and 3-4 layers in humans) [22]. Although the basal and intermediate urothelial cells are hardly distinguishable morphologically from their counterparts in other stratified epithelia, the superficial urothelial cells facing the bladder lumen, nick-named "umbrella cells", are highly distinct. These are large ( $\sim 100 \mu \mathrm{m}$ in diameter in rodents), polyhedral, and often bi-nucleated cells, thought to be derived from the intermediate cells via cell-cell fusion [33, 34]. Unlike any other cells in the body, the umbrella cells elaborate a membrane specialization, called asymmetric unit membrane (AUM), that lines over $95 \%$ of the apical surface of the urothelium as well as all the cytoplasmic fusiform vesicles [33-35]. It has been established that AUM is comprised of four major uroplakins (Ia, Ib, II and IIIa), and one minor uroplakin (IIIb), all of which are highly restricted to the urothelium [36-43]. While functionally active in synthesizing and assembling large amounts of uroplakins, the umbrella cells are considered to be terminally differentiated and incapable of undergoing cell division [22, 44], although some questions remain as to whether the umbrella cells can reenter the cell division cycle [45].

\section{Urothelial response to $\mathrm{pRb}$ deficiency}

It was unclear until recently as to why in molecular terms normal urothelium maintains an extremely low cycling rate. In addition to the lack of exposure of its basal cells to the urinary growth stimuli, urothelial cells are under the tight control of negative cell-cycle regulators. While p53, p16Ink4a, and p19Arf are consistently undetectable immunohistochemically [46, 47], all $\mathrm{pRb}$ family proteins, including $\mathrm{pRb}$ itself, p107 and p130, are uniformly expressed by all urothelial layers [48]. It appears, therefore, that the $\mathrm{pRb}$ family proteins play a redundant role in preventing urothelial cell-cycle progression, thus keeping its growth and proliferation to a minimum. If this were 
indeed the case, then one could predict that abrogation of one of the $\mathrm{pRb}$ family members would not be sufficient to accelerate urothelial growth or tumorigenesis and that the deficiency of one member might even lead to a compensatory induction of another. Both predictions have panned out. When $\mathrm{pRb}$ was ablated from the urothelium using a urothelium-specific Cre/lox system, no proliferative changes were observed, let alone the formation of flank urothelial tumors, despite an exhaustively long follow-up of a large cohort of pRb-knockout mice [48]. Instead, in pRbdeficient urothelial cells, there was a marked induction of p107 and its binding partners/transcription repressors E2F3 and E2F4 [48]. In contrast, p130 was largely unaffected. Additionally, the loss of $\mathrm{pRb}$ function in urothelium profoundly induced the p53 pathway signals including p19, p21, bax, and bak. These led to not only cell-cycle arrest but also to a widespread apoptotic response [48]. These data reveal several overlapping mechanisms whereby urothelial cells evade tumorigenesis during $\mathrm{pRb}$ deficiency and suggest that a collaborative event(s) may be required in order for $\mathrm{pRb}$ deficiency to be tumorigenic.

\section{Activation of RTK pathway components in low-grade non-invasive urothelial tumorigenesis}

Contrary to the resistance of urothelial cells to tumorigenesis during $\mathrm{pRb}$ and other tumor suppressor deficiency (see later), these cells are especially susceptible to RTK pathway activation [49]. Expression of a constitutively active Ha-ras in transgenic mouse urothelium elicited early-onset hyperplasia in all the mice, sixty percent of which eventually evolved, in mice older 10 months of age, to low-grade, noninvasive carcinomas that strongly resembled the human counterparts [50]. Surprisingly, ablation of the Ink4a gene, which encodes p16Ink4a and p19Arf tumor suppressors and whose deficiency synergizes with ras activation in many epithelial and mesenchymal tissues, failed to accelerate Ha-ras-induced urothelial hyper-proliferation or tumor formation [46]. In stark contrast, doubling the gene dosage of the activated Ha-ras in homozygous Ha-ras transgenic mice was sufficient to trigger early-onset non-invasive urothelial carcinomas (Fig. 1) [46]. Consistent with the proposed growth-inhibitory role of the $\mathrm{pRb}$ family in normal urothelium, all its members were markedly downregulated or undetectable in Ha-ras-induced urothelial hyperplasia or urothelial carcinomas [51]. Notably, activated Ha-rasinduced urothelial carcinomas are invariably low-grade and non-invasive, in spite of long-term observations [46, 50]. Generation and systematic dissection of urothelium-specific Ha-ras transgenic mice have, therefore, offered useful insights into urothelial tumorigenesis indicating that: (1) over-activation of Ha-ras is both necessary and sufficient to trigger urothelial tumors along the low-grade and noninvasive tumor pathway; (2) Ink4a gene products are not collaborative partners of ras activation in the urothelial context; and (3) downregulation of $\mathrm{pRb}$ family proteins is a prerequisite for urothelial tumor initiation [46, 49-51].

Additional evidence supporting a critical role of ras pathway activation in urothelial tumorigenesis comes from the human studies. It was recently discovered that Costello syndrome, a developmental disorder exhibiting musculoskeletal and nervous system malformation, is caused by germline mutations in the Ha-ras gene [12]. Patients with this syndrome begin to develop during early childhood and adolescence urothelial carcinomas that are of low pathological grade, multi-focal and recurrent, features that strikingly resemble low-grade, non-invasive urothelial carcinomas that bear sporadic Ha-ras mutations in adults [52-54]. Another piece of evidence relates to the finding that fibroblast growth factor receptor 3 (FGFR3), which is known to activate the ras signaling pathway $[55,56]$, is mutated in $50-80 \%$ of low-grade, non-invasive urothelial carcinomas in humans [57-59]. Mutations in FGFR3 most frequently involve the receptor's extracellular loop and affect the cysteine residues: either eliminating or creating a cysteine [49]. This results in cysteine mis-pairing, conformational change/misfolding and the failure of the mutated FGFR3 to exit the endoplasmic reticulum. Some FGFR3 mutants are capable of undergoing ligand-independent activation, constitutively stimulating down-stream effectors such as ras-GTPase [60, 61]. Interestingly, mutations of FGFR3 and Ha-ras rarely co-exist in the same tumor [62], possibly reflecting the functional equivalence of the mutations in these two genes. Given the fact that Ha-ras and FGFR 3 mutations each occur in $\sim 30 \%$ and $\sim 60 \%$ of the low-grade, non-invasive urothelial carcinomas [20, 57-59], there is reason to believe that mutations of these two genes can account for the overwhelming majority of this urothelial tumor variant [49]. It cannot be ruled out that the remainder of this tumor variant could be caused by mutations in other ras pathway components such as SOS and Raf-1 [63, 64] - a possibility that needs to be verified. Questions remain as to whether FGFR3 mutations alone are tumorigenic in transgenic mouse models; whether gene dosage of the FGFR3 mutants, like that of Ha-ras mutants, plays a role in tumor latency and penetrance; and whether FGFR3 mutations are required to collaborate with other tumorigenic event(s) to initiate urothelial carcinomas. Finally, FGFR3 mutations have been identified primarily in the low-grade urothelial carcinomas (50-80\%), multiple myelomas $(10-15 \%)$, and cervical carcinomas $(<5 \%)[65-$ 67]. It will be of considerable interest to find out why urothelial cells are particularly susceptible to FGFR3 mutations and whether this is related to a urotheliumspecific carcinogen. 


\section{Signaling Leading to Bladder Tumorigenesis along the Low-grade, Non-invasive Pathway}

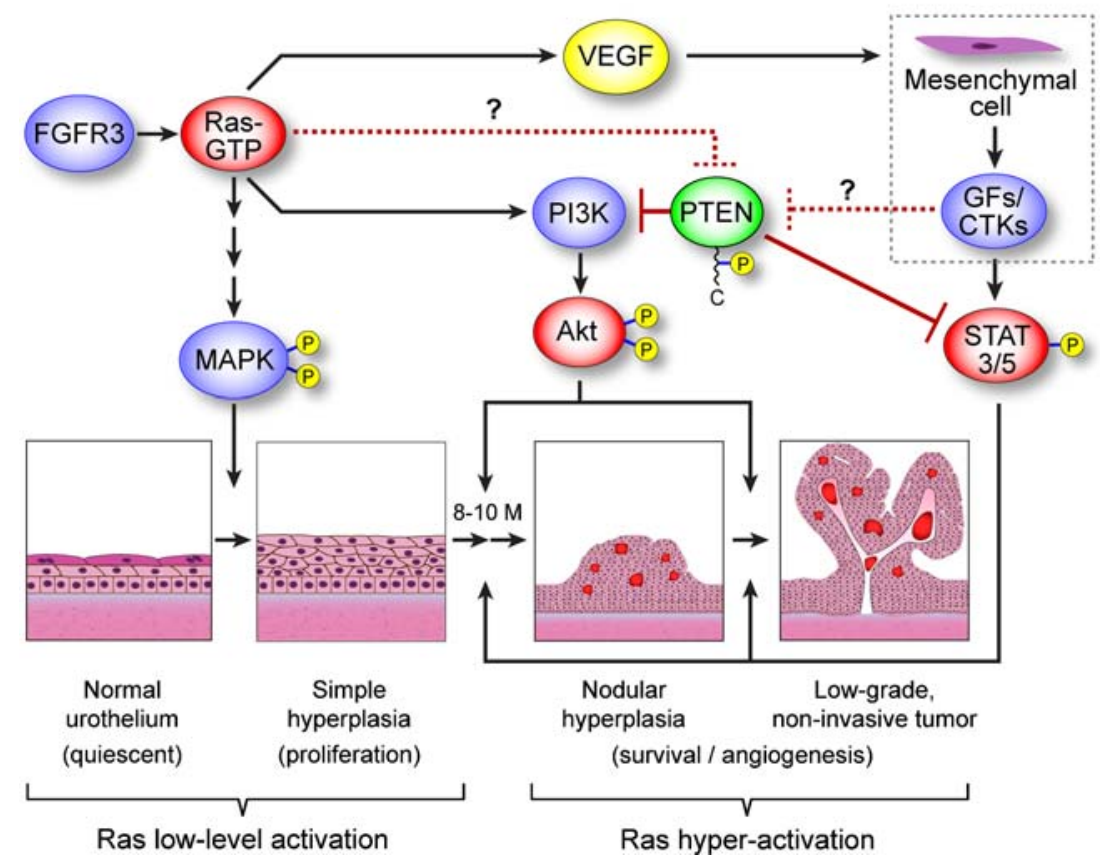

Fig. 1 Dosage-dependence in the activation of ras pathway effectors leading to low-grade, non-invasive urothelial tumorigenesis in the transgenic mice. Low-level urothelial expression of an activated Haras primarily induces MAPK pathway components and urothelial hyperplasia, without provoking urothelial tumors. However, doubling the activated Ha-ras transgene dosage hyper-activates Akt and STAT pathways, resulting in low-grade, non-invasive urothelial tumors.

STAT activation may be caused by growth factor $(G F s)$ and cytokines (CTKs) during epithelial/mesenchymal interaction and/or by the functional inactivation of PTEN through $\mathrm{C}$-terminal phosphorylation. Mutations in fibroblast growth factor receptor 3 (FGFR3), which is known to constitutively activate ras GTPase, are likely to transmit signals and induce urothelial tumors in a similar manner. This figure was reprinted with permission from Ref. 46

\section{Combined deficiency of pRb and p53 in invasive urothelial tumorigenesis}

For the last two decades, the combined defects of $\mathrm{pRb} / \mathrm{p} 53$ have been almost synonymous with the muscle-invasive urothelial carcinomas, largely because of the clinical correlation between the two [68]. About 50\% of the invasive urothelial carcinomas harbor p53 mutations and aberrant $\mathrm{pRb}$ expression simultaneously and these two alterations are more significantly associated with poor prognosis and patient survival than one alteration alone [69-71]. Despite the close clinical correlation, several technical constraints precluded the experimental verification of whether $\mathrm{pRb}$ and $\mathrm{p} 53$ deficiency is collaborative in initiating invasive urothelial carcinomas. $\mathrm{pRb}$ inactivation in mice in a global manner resulted in embryonic lethality due to severe abnormalities in hematopoietic and neurological systems [72-74]. Although mice globally defective in p53 survived to term, they succumbed to thymic lymphomas and soft tissue sarcomas 3-7 months of age when urothelium appeared completely normal $[14,47]$. The lack of early-onset urothelial tumorigenesis in global p53 knockout mice suggests that p53 deficiency is insufficient

to provoke urothelial tumors, although one could argue that the combined deficiency of p53 and pRb may be sufficient. Such a scenario could be supported in part by the compensatory induction of p53 pathway in pRb-deficient cells and by the fact that defects of the two genes co-exist in nearly half of the muscle-invasive bladder cancers in humans [69-71]. With the help of a urothelium-specific knockout system [75], pRb and p53 were recently ablated either alone or in a combination in the urothelial cells [48]. Unlike the global p53 knockout where mice died early in life, conditional p53 inactivation permitted analyses of the long-term urothelial effects of p53 deficiency. Nevertheless, with the exception of late-onset, localized urothelial atypia, no urothelial tumors were detected throughout the 30month observation period [48]. Therefore, p53 deficiency per se, like that of $\mathrm{pRb}$, is not tumorigenic within the urothelial context. When p53 deficiency was combined with $\mathrm{pRb}$ deficiency in the double knockout mice, the former effectively abrogated the cell-cycle arrest and apoptotic responses provoked by the latter. Unexpectedly, however, even the combined deficiency of p53 and pRb only produced late-onset, simple urothelial hyperplasia, and low-grade, superficial papillary tumors in a small fraction 
$(<5 \%)$ of the double knockout mice [48]. No invasive urothelial carcinoma was observed despite long-term observations of several independent cohorts. While incapable of forming full-fledged invasive carcinomas spontaneously, $50 \%$ of the p53/pRb-double null mice developed muscle-invasive urothelial carcinomas after exposure to a $0.01 \%$ BBN for 10 weeks [48]. At the same dosage and time frame, none of the single-null mice lacking either p53 or $\mathrm{pRb}$, or the double null mice lacking one p53 and one $\mathrm{pRb}$ allele, developed any urothelial tumors. Taken together, these data provide compelling experimental evidence indicating that the combined defects of $\mathrm{p} 53$ and $\mathrm{pRb}$ are necessary but not sufficient to initiate invasive urothelial carcinomas and suggest that other genetic alterations are required to trigger this urothelial tumor type. Given the fact that conditional inactivation of both $\mathrm{p} 53$ and $\mathrm{pRb}$ elicits flank tumors in several non-epithelial tissues $[76,77]$, the observed effects with these two genes deleted in the urothelial cells provide yet another example of the contextdependency of tumorigenicity not only by oncogenes, but also by tumor suppressor genes.

\section{Potential involvement of $\mathrm{pRb}$ family proteins in invasive urothelial tumorigenesis}

The lack of tumorigenesis in urothelial cells deficient for both $\mathrm{p} 53$ and $\mathrm{pRb}$ created a discrepancy with results obtained from transgenic mice urothelially expressing an SV40 large $T$ antigen, which is known to functionally inactivate $\mathrm{p} 53$ and $\mathrm{pRb}$. These mice, particularly those harboring high SV40T transgene copies, consistently developed high-grade urothelial lesions resembling carcinoma in situ followed by muscle invasion and metastasis $[78,79]$. Similar results of invasive urothelial tumorigenesis were obtained from an independent transgenic model in which SV40T was driven by a keratin 5 promoter that is transcriptionally active in urothelial as well as several nonurothelial epithelial tissues [80]. Although the oncogenic effects of SV40T reach well beyond its ability to inactivate p53 and pRb, the specific inhibitory effect of SV40T on the entire $\mathrm{pRb}$ family proteins such as p107 and p130 is of particular interest $[16,81]$. As discussed earlier, there was a marked induction of p107 in urothelial cells deficient for $\mathrm{pRb}$ [48]. This response remained high when the urothelial cells were made both $\mathrm{pRb}$ - and p53-deficient. In both situations, p107 induction was accompanied by an increased expression of E2F3 and E2F4, two transcription repressors/growth inhibitors.

p107 shares a similar structure with the other two pRb family members ( $\mathrm{pRb}$ and $\mathrm{p} 130)$ in possessing a pocket domain for protein interaction and they act in concert to restrict cell-cycle progression from $\mathrm{G} 1$ to $\mathrm{S}$ and from $\mathrm{G} 2$ to
$M$ phases [82, 83]. Emerging evidence suggests that different $\mathrm{pRb}$ family proteins may carry out distinct functions by partnering with different downstream E2F effectors. For instance, $\mathrm{pRb}$ binds to so-called activating E2Fs including E2F1, 2 and 3a, whereas p107 and p130 bind to repressive E2Fs such as E2F3b, 4 and 5 [84]. Because E2F4 and 5 do not have a nuclear translocation signal, their binding to p107 and p130 is crucial for their role in transcription repression. While $\mathrm{pRb}$ was a wellestablished tumor suppressor, the role of p107 and p130 in tumorigenesis is much less clear.

It appears that p107 induction in urothelium may represent a compensatory tumor defense in response to $\mathrm{pRb}$ deficiency and that p107 deficiency could be synergistic with $\mathrm{pRb}$ and $\mathrm{p} 53$ deficiency to trigger urothelial tumor formation (Fig. 2). Indeed, in BBN-treated pRb/p53 double null mice that developed invasive urothelial carcinomas, p107 was significantly downregulated [48]. A close collaborative role between p107 deficiency and that of pRb and $\mathrm{p} 53$ has been demonstrated in retinal and epidermal tumorigenesis $[85,86]$. Direct proof of whether this synergistic role applies to the urothelial cells has yet to be made available, perhaps via the generation of compound knockout mice lacking all three proteins.
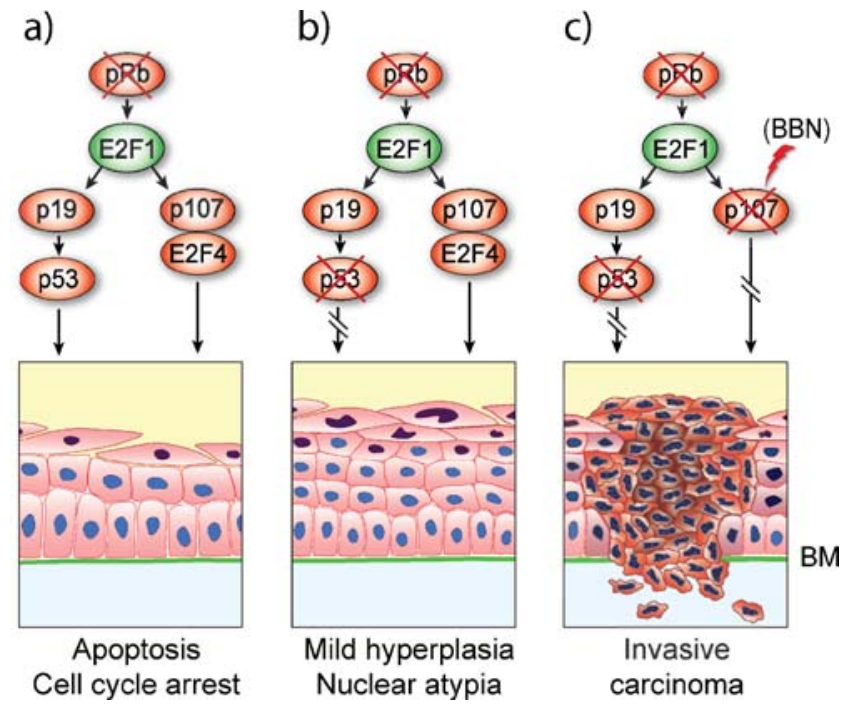

Fig. 2 Collaborative effects between pRb family proteins and p53 in invasive urothelial tumorigenesis. a Ablation of $\mathrm{pRb}$ specifically in urothelium leads to E2F1 over-expression which in turn up-regulates the p53 pathway and pRb family protein p107 along with transcriptional repressor E2F4. These compensatory urothelial defenses cause urothelial cells to undergo cell-cycle arrest and apoptosis. b Additional ablation of p53 in urothelial cells lacking pRb effectively blunted apoptotic response, resulting in late-onset hyperplasia and nuclear atypia. c Treatment of urothelial cells lacking both $\mathrm{pRb}$ and p53 with bladder carcinogen BBN down-regulates p107 and triggers invasive urothelial tumorigenesis. This model emphasizes the collaborative effects among pRb family proteins and p53 in invasive urothelial tumor initiation. This figure was reprinted with permission from Ref. 48 


\section{Emerging role of PTEN deficiency}

The phosphatase and tensin homology (or PTEN), located on human chromosome 10 , is a lipid phosphatase that dephosphorylates phosphoinositide-3,4,5-triphosphate (PI3P). In doing so, the $55-\mathrm{kDa}$ protein antagonizes the activity of PI3 kinase, preventing it from activating downstream pro-proliferation and -survival signals, especially AKT, and leading to growth inhibition [87, 88]. Inactivation of PTEN in vitro enhances oncogenic transformation and reintroduction of PTEN in cells lacking it suppresses cell growth [89-91]. While homozygous deletion of PTEN in mice causes embryonic lethality [92], mice heterozygous for the gene develop multi-organ tumors particularly those of endometrium, liver, prostate, and thyroid [93]. Tumor formation in heterozygous mice is associated with a concomitant loss of the wild-type allele in the tumor cells, suggesting that, like most other tumor suppressors, inactivation of both alleles is required for complete gene inactivation [93, 94]. This concept of inactivation of both tumor suppressor gene alleles as a prerequisite for tumor predisposition has received strong support from more recent tissue-specific PTEN knockout models $[95,96]$. Not surprisingly, loss-of-function mutations or deletion of PTEN have become one of the most commonly identified mutations in human tumors [87, 97]. Finally, patients with Cowden's disease and other related syndromes that harbor germline mutations in the PTEN gene are susceptible to tumor formation, particularly in the mammary and thyroid glands [98]. These and other observations firmly establish PTEN as a potent tumor suppressor whose deficiency plays a major role in the tumorigenic process.

Although PTEN has been proven to be a general tumor suppressor, little was known until recently about whether its deficiency plays a significant role in bladder tumorigenesis. Ablation of loxP-flanked PTEN by Cre recombinase under the control of the promoter of fatty acid binding protein 1 gene, which restricted PTEN inactivation to mainly genitourinary tissues, elicited urothelial hyperplasia and a low percentage (10-20\%) of bladder tumors after long-term follow-up [95, 99]. These data suggest that the absence of PTEN alone is insufficient for bladder tumor initiation and that PTEN deficiency requires another genetic event to be fully tumorigenic. An interesting study published recently pointed to the possibility that $\mathrm{p} 53$ deficiency could be such a pivotal collaborating event [100]. By codeleting loxP-flanked PTEN and p53 genes in the bladder using an intravesically instilled, adenovirus-driven Cre recombinase, the authors found invasive bladder carcinomas in the double knockout mice, but not in the single gene knockout mice. Consistent with the loss of PTEN as an upstream inhibitor of PI3K/AKT signaling pathway, tumor formation in the double null mice was associated with a strong activation of mammalian target of rapamycin (mTOR) [100]. In the same study, the authors found codeletion of "floxed" p53 and pRb in the urothelium by adenovirus-driven Cre not to be tumorigenic, thus lending independent support to the results obtained from $\mathrm{p} 53 / \mathrm{pRb}$ inactivation via constitutively expressed urothelial Cre (see Section 5).

As for human studies, several independent groups found allelic loss or imbalance of chromosome 10q, where PTEN resides, to be present in $30-50 \%$ of the human bladder tumors [101-105]. However, homozygous deletion of PTEN occurs in only about $0-6 \%$ of the tumors. Surprisingly, in patients exhibiting loss of one PTEN allele, mutations in the remaining allele are infrequent, ranging from $0-10 \%$ in most cohorts $[101,106,107]$. On a protein level, absent PTEN expression is found in $\sim 6 \%$ of the tumors, a rate similar to that of homozygous gene deletion [99]. Together, these data reveal a recurring theme that structural damage affecting both PTEN alleles is infrequent in the majority of human bladder cancers, raising the interesting possibility that functional inactivation of PTEN contributes significantly to PTEN deficiency. This is clearly an important area that requires further investigation.

\section{Mechanisms of urothelial tumor progression}

One of the key findings from the genetically engineered mice is that distinct genetic alterations clearly underlie phenotypically divergent urothelial tumors. Thus, ras pathway activation produces exclusively the low-grade, non-invasive urothelial carcinomas $[46,50]$. On the other hand, p53 inactivation along with deficiency in the $\mathrm{pRb}$ family proteins or in PTEN is almost exclusively associated with high-grade, invasive urothelial carcinomas [48, 100]. Thus far, few studies have been carried out to examine what genetic or epigenetic alterations are responsible for converting the low-grade non-invasive urothelial tumors into the high-grade invasive ones. Although a number of factors could come into play, the low-grade urothelial tumors triggered by the Ha-ras mutation seem to have acquired several major tumor barriers, as evidenced by the induction of multiple CDK inhibitors/tumor suppressors such as p15, p16, p21, p27, and p53 [46, 51]. These molecules are known to play important roles in mediating premature senescence, apoptosis, and DNA damage response. It is conceivable that overcoming one or more barriers will be necessary in order for the low-grade urothelial tumors to transit to high-grade ones. Understanding this important issue will help provide new clues as to how the progression of urothelial tumors can be more accurately predicted clinically. 


\section{Diagnostic and therapeutic implications}

As the molecular bases distinguishing the two urothelial carcinoma variants start to be unraveled, it is more realistic than ever to devise variant-specific intervention strategies. Because ras pathway activation accounts for an overwhelming majority of the low-grade non-invasive urothelial carcinomas, inhibitors of key pathway effectors in particular FGFR3, ras, Akt, Stat3/5, will likely have an important therapeutic effect in treating and/or reducing the recurrence frequency of this major urothelial tumor variant [46, 49]. Such pharmaceutical-based therapies will significantly reduce the need for surgical intervention, thus minimizing patient suffering and economic burden. Similarly, the findings that deficiency of $\mathrm{p} 53$ cooperates with that of $\mathrm{pRb}$ and $\mathrm{p} 107$ or PTEN to induce invasive urothelial carcinomas $[48,100]$ suggest that replacing and/or restoring the function of one or more of these tumor suppressors could be an attractive alternative or an adjunct to radical cystectomy and chemotherapy for this often deadly urothelial tumor variant. Viral vector-based gene therapies based on $\mathrm{pRb}$ or $\mathrm{p} 53$ alone have already been tested for human urothelial carcinomas, showing early promise [108, 109]. Combination therapies that include not just one but two or more wild-type tumor suppressors will likely be more effective than single gene therapy. Finally, a combination of the currently used markers such as p53 and pRb with newer markers such as p107 and PTEN could be more reliable than single markers in predicting the prognosis of patients with bladder cancers $[48,100]$.

\section{Summary and prospective}

Since the introduction of transgenic and knockout models into the bladder cancer field, the technology has been instrumental for improving the understanding of the molecular pathogenesis of this disease. It has helped better define the tumorigenicity, or the lack thereof, of oncogenic alterations prevalent in human bladder cancer specimens; identify key signals whose activation drives urothelial tumorigenesis and progression; understand the intricate interplay and the collaborative relationships among diverse oncogenic defects; reveal distinct lesions preceding the development of a urothelial tumor variant; attach specific meanings to why there are phenotypically divergent pathways of urothelial tumorigenesis; and provide in vivo platforms for testing novel preventive and therapeutic strategies. Such information has been proven quite complementary to that obtained from the analysis of human specimens. The hypotheses generated from the animal models are readily testable in humans as well. Looking ahead, there is still a great deal to be learned about what underlies each of the two major pathways of urothelial tumorigenesis. For instance, while ras pathway activation could account for an overwhelming majority of the lowgrade non-invasive urothelial carcinomas, about half of the muscle-invasive urothelial carcinomas in humans have no known defects in $\mathrm{p} 53, \mathrm{pRb}$, or PTEN. Are these tumors caused by some of the known genetic defects or by other yetto-identified genetic defects? As the transgenic/knockout technology matures, new questions can be asked with new levels of sophistication. There should be little doubt that future models will be more useful and relevant than those now in existence in helping elucidate the molecular pathogenesis of bladder cancer and improve target-based clinical management.

Acknowledgments The author would like to acknowledge the research support from the National Institutes of Health and the Veterans Affairs Administration.

Open Access This article is distributed under the terms of the Creative Commons Attribution Noncommercial License which permits any noncommercial use, distribution, and reproduction in any medium, provided the original author(s) and source are credited.

\section{References}

1. Hanahan, D., \& Weinberg, R. A. (2000). The hallmarks of cancer. Cell, 100, 57-70.

2. Jones, P. A., \& Baylin, S. B. (2007). The epigenomics of cancer. Cell, 128, 683-692.

3. Stratton, M. R., Campbell, P. J., \& Futreal, P. A. (2009). The cancer genome. Nature, 458, 719-724.

4. Hunter, K. W. (2006). Context-dependent cancer risk. Nature Genetics, 38, 864-865.

5. Kinzler, K. W., \& Vogelstein, B. (1996). Lessons from hereditary colorectal cancer. Cell, 87, 159-170.

6. Nathke, I. (2006). Cytoskeleton out of the cupboard: Colon cancer and cytoskeletal changes induced by loss of APC. Nature Reviews Cancer, 6, 967-974.

7. de la Chapelle, A. (2004). Genetic predisposition to colorectal cancer. Nature Reviews Cancer, 4, 769-780.

8. Linehan, W. M., \& Zbar, B. (2004). Focus on kidney cancer. Cancer Cell, 6, 223-228.

9. Kim, W. Y., \& Kaelin, W. G. (2004). Role of VHL gene mutation in human cancer. Journal of Clinical Oncology, 22, 4991-5004.

10. Malkin, D. (1994). Germline p53 mutations and heritable cancer. Annual Review of Genetics, 28, 443-465.

11. Li, F. P., Fraumeni, J. F., Jr., Mulvihill, J. J., Blattner, W. A., Dreyfus, M. G., Tucker, M. A., et al. (1988). A cancer family syndrome in twenty-four kindreds. Cancer Research, 48, 53585362.

12. Aoki, Y., Niihori, T., Kawame, H., Kurosawa, K., Ohashi, H., Tanaka, Y., et al. (2005). Germline mutations in HRAS protooncogene cause Costello syndrome. Nature Genetics, 37, 10381040.

13. Gripp, K. W. (2005). Tumor predisposition in Costello syndrome. American Journal of Medical Genetics. Part C, Seminars in Medical Genetics, 137, 72-77.

14. Donehower, L. A., Harvey, M., Slagle, B. L., McArthur, M. J., Montgomery, C. A., Jr., Butel, J. S., et al. (1992). Mice deficient 
for p53 are developmentally normal but susceptible to spontaneous tumours. Nature, 356, 215-221.

15. Watt, F. M., Frye, M., \& Benitah, S. A. (2008). MYC in mammalian epidermis: how can an oncogene stimulate differentiation? Nature Review Cancer, 8, 234-242.

16. Ahuja, D., Saenz-Robles, M. T., \& Pipas, J. M. (2005). SV40 large $T$ antigen targets multiple cellular pathways to elicit cellular transformation. Oncogene, 24, 7729-7745.

17. Rassoulzadegan, M., \& Cuzin, F. (1987). "Sub-threshold neoplastic states" created in transgenic mice. Oncogene Research, 1, 1-6.

18. Ghebranious, N., \& Donehower, L. A. (1998). Mouse models in tumor suppression. Oncogene, 17, 3385-3400.

19. Wu, X.-R., Sun, T.-T., McConkey, D. J., Shrader, M., \& Papageorgiou, A. (2006). Animal models of bladder cancer. In S. P. Lerner, M. P. Schoenberg \& C. N. Sternberg (Eds.), Textbook of bladder cancer (pp. 157-169). Boca Raton: Taylor \& Francis.

20. Dinney, C. P., McConkey, D. J., Millikan, R. E., Wu, X., Bar-Eli, M., Adam, L., et al. (2004). Focus on bladder cancer. Cancer Cell, 6, 111-116.

21. Cohen, S. M. (2002). Comparative pathology of proliferative lesions of the urinary bladder. Toxicologic Pathology, 30, 663-671.

22. Wu, X. R., Kong, X. P., Pellicer, A., Kreibich, G., \& Sun, T. T. (2009). Uroplakins in urothelial biology, function, and disease. Kidney International, 75, 1153-1165.

23. Sun, T. T. (2006). Altered phenotype of cultured urothelial and other stratified epithelial cells: implications for wound healing. American Journal of Physiology and Renal Physiology, 291, F9F21.

24. Khandelwal, P., Abraham, S. N., \& Apodaca, G. (2009). Cell biology and physiology of the uroepithelium. American Journal of Physiology and Renal Physiology (in press)

25. Lewis, S. A. (2000). Everything you wanted to know about the bladder epithelium but were afraid to ask. American Journal of Physiology and Renal Physiology, 278, F867-F874.

26. Negrete, H. O., Lavelle, J. P., Berg, J., Lewis, S. A., \& Zeidel, M. L. (1996). Permeability properties of the intact mammalian bladder epithelium. American Journal of Physiology, 271, F886F894.

27. Hicks, R. M. (1975). The mammalian urinary bladder: An accommodating organ. Biological Reviews of the Cambridge Philosophical Society, 50, 215-246.

28. Walker, R. E. (1960). Renewal of cell populations in the female mouse. American Journal of Anatomy, 102, 95-100.

29. Kurzrock, E. A., Lieu, D. K., Degraffenried, L. A., Chan, C. W., \& Isseroff, R. R. (2008). Label-retaining cells of the bladder: candidate urothelial stem cells. American Journal of Physiology and Renal Physiology, 294, F1415-F1421.

30. Chow, N. H., Liu, H. S., Yang, H. B., Chan, S. H., \& Su, I. J. (1997). Expression patterns of erbB receptor family in normal urothelium and transitional cell carcinoma. An immunohistochemical study. Virchows Archiv, 430, 461-466.

31. Messing, E. M. (1990). Clinical implications of the expression of epidermal growth factor receptors in human transitional cell carcinoma. Cancer Research, 50, 2530-2537.

32. Messing, E. M. (1992). Growth factors and bladder cancer: clinical implications of the interactions between growth factors and their urothelial receptors. Seminars in Surgical Oncology, 8, 285-292.

33. Hicks, R. M. (1965). The fine structure of the transitional epithelium of rat ureter. Journal of Cell Biology, 26, 25-48.

34. Koss, L. G. (1969). The asymmetric unit membranes of the epithelium of the urinary bladder of the rat. An electron microscopic study of a mechanism of epithelial maturation and function. Laboratory Investigation, 21, 154-168.

35. Porter, K. R., \& Bonneville, M. A. (1963). An introduction to the fine structure of cells and tissues. Philadelphia: Lea \& Febiger.
36. Wu, X. R., \& Sun, T. T. (1993). Molecular cloning of a $47 \mathrm{kDa}$ tissue-specific and differentiation-dependent urothelial cell surface glycoprotein. Journal of Cell Science, 106, 31-43.

37. Lin, J. H., Wu, X. R., Kreibich, G., \& Sun, T. T. (1994). Precursor sequence, processing, and urothelium-specific expression of a major $15-\mathrm{kDa}$ protein subunit of asymmetric unit membrane. Journal of Biological Chemistry, 269, 1775-1784.

38. Yu, J., Lin, J. H., Wu, X. R., \& Sun, T. T. (1994). Uroplakins Ia and $\mathrm{Ib}$, two major differentiation products of bladder epithelium, belong to a family of four transmembrane domain (4TM) proteins. Journal of Cell Biology, 125, 171-182.

39. Yu, J., Manabe, M., Wu, X. R., Xu, C., Surya, B., \& Sun, T. T. (1990). Uroplakin I: a $27-\mathrm{kD}$ protein associated with the asymmetric unit membrane of mammalian urothelium. Journal Cell Biology, 111, 1207-1216.

40. Wu, X. R., Lin, J. H., Walz, T., Haner, M., Yu, J., Aebi, U., et al. (1994). Mammalian uroplakins. A group of highly conserved urothelial differentiation-related membrane proteins. Journal of Biological Chemistry, 269, 13716-13724.

41. Deng, F. M., Liang, F. X., Tu, L., Resing, K. A., Hu, P., Supino, M., et al. (2002). Uroplakin IIIb, a urothelial differentiation marker, dimerizes with uroplakin $\mathrm{Ib}$ as an early step of urothelial plaque assembly. Journal of Cell Biology, 159, 685-694.

42. Moll, R., Wu, X. R., Lin, J. H., \& Sun, T. T. (1995). Uroplakins, specific membrane proteins of urothelial umbrella cells, as histological markers of metastatic transitional cell carcinomas. American Journal of Pathology, 147, 1383-1397.

43. Wu, R. L., Osman, I., Wu, X. R., Lu, M. L., Zhang, Z. F., Liang, F. X., et al. (1998). Uroplakin II gene is expressed in transitional cell carcinoma but not in bilharzial bladder squamous cell carcinoma: alternative pathways of bladder epithelial differentiation and tumor formation [published erratum appears in Cancer Res 1998 Jul 1;58(13):2904]. Cancer Research, 58, 1291-1297.

44. Cheng, J., Huang, H., Zhang, Z. T., Shapiro, E., Pellicer, A., Sun, T. T., et al. (2002). Overexpression of epidermal growth factor receptor in urothelium elicits urothelial hyperplasia and promotes bladder tumor growth. Cancer Research, 62, 41574163.

45. Signoretti, S., Pires, M. M., Lindauer, M., Horner, J. W., Grisanzio, C., Dhar, S., et al. (2005). p63 regulates commitment to the prostate cell lineage. Proceedings of the National Academy of Sciences of the United States of America, 102, 11355-11360.

46. Mo, L., Zheng, X., Huang, H. Y., Shapiro, E., Lepor, H., Cordon-Cardo, C., et al. (2007). Hyperactivation of Ha-ras oncogene, but not Ink4a/Arf deficiency, triggers bladder tumorigenesis. Journal of Clinical Investigation, 117, 314-325.

47. Gao, J., Huang, H. Y., Pak, J., Cheng, J., Zhang, Z. T., Shapiro, E., et al. (2004). p53 deficiency provokes urothelial proliferation and synergizes with activated Ha-ras in promoting urothelial tumorigenesis. Oncogene, 23, 687-696.

48. He, F., Mo, L., Zheng, X. -Y., Hu, C., Lepor, H., Lee, E. Y.-H. P., et al. (2009). Deficiency of pRb family proteins and p53 in invasive urothelial tumorigenesis. Cancer Research (in press)

49. Wu, X. R. (2005). Urothelial tumorigenesis: A tale of divergent pathways. Nature Reviews Cancer, 5, 713-725.

50. Zhang, Z. T., Pak, J., Huang, H. Y., Shapiro, E., Sun, T. T., Pellicer, A., et al. (2001). Role of Ha-ras activation in superficial papillary pathway of urothelial tumor formation. Oncogene, 20, 1973-1980.

51. Garcia-Espana, A., Salazar, E., Sun, T. T., Wu, X. R., \& Pellicer, A. (2005). Differential expression of cell cycle regulators in phenotypic variants of transgenically induced bladder tumors: implications for tumor behavior. Cancer Research, 65, 1150-1157.

52. Franceschini, P., Licata, D., Di Cara, G., Guala, A., Bianchi, M., Ingrosso, G., et al. (1999). Bladder carcinoma in Costello syndrome: report on a patient born to consanguineous parents 
and review. American Journal of Medical Genetics, 86, 174179.

53. Gripp, K. W., Scott, C. I., Jr., Nicholson, L., \& Figueroa, T. E. (2000). Second case of bladder carcinoma in a patient with Costello syndrome. American Journal of Medical Genetics, 90, 256-259.

54. Urakami, S., Igawa, M., Shiina, H., Shigeno, K., Kikuno, N., \& Yoshino, T. (2002). Recurrent transitional cell carcinoma in a child with the Costello syndrome. Journal of Urology, 168, 1133-1134.

55. Agazie, Y. M., Movilla, N., Ischenko, I., \& Hayman, M. J. (2003). The phosphotyrosine phosphatase SHP2 is a critical mediator of transformation induced by the oncogenic fibroblast growth factor receptor 3. Oncogene, 22, 6909-6918.

56. Kanai, M., Goke, M., Tsunekawa, S., \& Podolsky, D. K. (1997). Signal transduction pathway of human fibroblast growth factor receptor 3. Identification of a novel 66-kDa phosphoprotein. Journal of Biological Chemistry, 272, 6621-6628.

57. Cappellen, D., De Oliveira, C., Ricol, D., de Medina, S., Bourdin, J., Sastre-Garau, X., et al. (1999). Frequent activating mutations of FGFR3 in human bladder and cervix carcinomas. Nature Genetics, 23, 18-20.

58. Rieger-Christ, K. M., Mourtzinos, A., Lee, P. J., Zagha, R. M., Cain, J., Silverman, M., et al. (2003). Identification of fibroblast growth factor receptor 3 mutations in urine sediment DNA samples complements cytology in bladder tumor detection. Cancer, 98, 737-744.

59. van Rhijn, B. W., van der Kwast, T. H., Vis, A. N., Kirkels, W. J., Boeve, E. R., Jobsis, A. C., et al. (2004). FGFR3 and P53 characterize alternative genetic pathways in the pathogenesis of urothelial cell carcinoma. Cancer Research, 64, 1911-1914.

60. Naski, M. C., Wang, Q., Xu, J., \& Ornitz, D. M. (1996). Graded activation of fibroblast growth factor receptor 3 by mutations causing achondroplasia and thanatophoric dysplasia. Nature Genetics, 13, 233-237.

61. Monsonego-Ornan, E., Adar, R., Feferman, T., Segev, O., \& Yayon, A. (2000). The transmembrane mutation G380R in fibroblast growth factor receptor 3 uncouples ligand-mediated receptor activation from down-regulation. Molecular and Cellular Biology, 20, 516-522.

62. Jebar, A. H., Hurst, C. D., Tomlinson, D. C., Johnston, C., Taylor, C. F., \& Knowles, M. A. (2005). FGFR3 and Ras gene mutations are mutually exclusive genetic events in urothelial cell carcinoma. Oncogene, 24, 5218-5225.

63. Tartaglia, M., Pennacchio, L. A., Zhao, C., Yadav, K. K., Fodale, V., Sarkozy, A., et al. (2007). Gain-of-function SOS1 mutations cause a distinctive form of Noonan syndrome. Nature Genetics, $39,75-79$.

64. Madhunapantula, S. V., \& Robertson, G. P. (2008). Is B-Raf a good therapeutic target for melanoma and other malignancies? Cancer Research, 68, 5-8.

65. Sibley, K., Stern, P., \& Knowles, M. A. (2001). Frequency of fibroblast growth factor receptor 3 mutations in sporadic tumours. Oncogene, 20, 4416-4418.

66. Wu, R., Connolly, D., Ngelangel, C., Bosch, F. X., Munoz, N., \& Cho, K. R. (2000). Somatic mutations of fibroblast growth factor receptor 3 (FGFR3) are uncommon in carcinomas of the uterine cervix. Oncogene, 19, 5543-5546.

67. Fracchiolla, N. S., Luminari, S., Baldini, L., Lombardi, L., Maiolo, A. T., \& Neri, A. (1998). FGFR3 gene mutations associated with human skeletal disorders occur rarely in multiple myeloma. Blood, 92, 2987-2989.

68. Reznikoff, C. A., Belair, C. D., Yeager, T. R., Savelieva, E., Blelloch, R. H., Puthenveettil, J. A., et al. (1996). A molecular genetic model of human bladder cancer pathogenesis. Seminars in Oncology, 23, 571-584.
69. Cote, R. J., Dunn, M. D., Chatterjee, S. J., Stein, J. P., Shi, S. R., Tran, Q. C., et al. (1998). Elevated and absent pRb expression is associated with bladder cancer progression and has cooperative effects with p53. Cancer Research, 58, 1090-1094.

70. Grossman, H. B., Liebert, M., Antelo, M., Dinney, C. P., Hu, S. X., Palmer, J. L., et al. (1998). p53 and Rb expression predict progression in T1 bladder cancer. Clinical Cancer Research, 4, 829-834.

71. Cordon-Cardo, C., Zhang, Z. F., Dalbagni, G., Drobnjak, M., Charytonowicz, E., Hu, S. X., et al. (1997). Cooperative effects of $\mathrm{p} 53$ and $\mathrm{pRB}$ alterations in primary superficial bladder tumors. Cancer Research, 57, 1217-1221.

72. Clarke, A. R., Maandag, E. R., van Roon, M., van der Lugt, N. M., van der Valk, M., Hooper, M. L., et al. (1992). Requirement for a functional Rb-1 gene in murine development. Nature, 359, 328-330.

73. Jacks, T., Fazeli, A., Schmitt, E. M., Bronson, R. T., Goodell, M. A., \& Weinberg, R. A. (1992). Effects of an Rb mutation in the mouse. Nature, 359, 295-300.

74. Lee, E. Y., Chang, C. Y., Hu, N., Wang, Y. C., Lai, C. C., Herrup, K., et al. (1992). Mice deficient for Rb are nonviable and show defects in neurogenesis and haematopoiesis. Nature, 359, 288-294.

75. Mo, L., Cheng, J., Lee, E. Y., Sun, T. T., \& Wu, X. R. (2005). Gene deletion in urothelium by specific expression of Cre recombinase. American Journal of Physiology and Renal Physiology, 289, F562-F568.

76. Flesken-Nikitin, A., Choi, K. C., Eng, J. P., Shmidt, E. N., \& Nikitin, A. Y. (2003). Induction of carcinogenesis by concurrent inactivation of p53 and $\mathrm{Rb} 1$ in the mouse ovarian surface epithelium. Cancer Research, 63, 3459-3463.

77. Marino, S., Vooijs, M., van Der Gulden, H., Jonkers, J., \& Berns, A. (2000). Induction of medulloblastomas in p53-null mutant mice by somatic inactivation of $\mathrm{Rb}$ in the external granular layer cells of the cerebellum. Genes and Development, 14, 994-1004.

78. Cheng, J., Huang, H., Pak, J., Shapiro, E., Sun, T. T., CordonCardo, C., et al. (2003). Allelic loss of p53 gene is associated with genesis and maintenance, but not invasion, of mouse carcinoma in situ of the bladder. Cancer Research, 63, 179-185.

79. Zhang, Z. T., Pak, J., Shapiro, E., Sun, T. T., \& Wu, X. R. (1999). Urothelium-specific expression of an oncogene in transgenic mice induced the formation of carcinoma in situ and invasive transitional cell carcinoma. Cancer Research, 59, 35123517.

80. Grippo, P. J., \& Sandgren, E. P. (2000). Highly invasive transitional cell carcinoma of the bladder in a simian virus 40 T-antigen transgenic mouse model. American Journal of Pathology, 157, 805-813.

81. Ali, S. H., \& DeCaprio, J. A. (2001). Cellular transformation by SV40 large T antigen: interaction with host proteins. Seminars in Cancer Biology, 11, 15-23.

82. Sun, A., Bagella, L., Tutton, S., Romano, G., \& Giordano, A. (2007). From G0 to S phase: a view of the roles played by the retinoblastoma $(\mathrm{Rb})$ family members in the Rb-E2F pathway. Journal of Cellular Biochemistry, 102, 1400-1404.

83. Vidal, A., Carneiro, C., \& Zalvide, J. B. (2007). Of mice without pockets: mouse models to study the function of $\mathrm{Rb}$ family proteins. Front and Bioscience, 12, 4483-4496.

84. Crosby, M. E., \& Almasan, A. (2004). Opposing roles of E2Fs in cell proliferation and death. Cancer Biology Therapeutic, 3, 1208-1211.

85. MacPherson, D., Sage, J., Kim, T., Ho, D., McLaughlin, M. E., \& Jacks, T. (2004). Cell type-specific effects of Rb deletion in the murine retina. Genes and Development, 18, 1681-1694.

86. Lara, M. F., Santos, M., Ruiz, S., Segrelles, C., Moral, M., Martinez-Cruz, A. B., et al. (2008). p107 acts as a tumor 
suppressor in pRb-deficient epidermis. Molecular Carcinogenesis, 47, 105-113.

87. Chow, L. M., \& Baker, S. J. (2006). PTEN function in normal and neoplastic growth. Cancer Letters, 241, 184-196.

88. Vazquez, F., Matsuoka, S., Sellers, W. R., Yanagida, T., Ueda, M., \& Devreotes, P. N. (2006). Tumor suppressor PTEN acts through dynamic interaction with the plasma membrane. Proceedings of the National Academy of Sciences of the United States of America, 103, 3633-3638.

89. Tanaka, M., Koul, D., Davies, M. A., Liebert, M., Steck, P. A., \& Grossman, H. B. (2000). MMAC1/PTEN inhibits cell growth and induces chemosensitivity to doxorubicin in human bladder cancer cells. Oncogene, 19, 5406-5412.

90. Gildea, J. J., Herlevsen, M., Harding, M. A., Gulding, K. M., Moskaluk, C. A., Frierson, H. F., et al. (2004). PTEN can inhibit in vitro organotypic and in vivo orthotopic invasion of human bladder cancer cells even in the absence of its lipid phosphatase activity. Oncogene, 23, 6788-6797.

91. Li, J., Simpson, L., Takahashi, M., Miliaresis, C., Myers, M. P., Tonks, N., et al. (1998). The PTEN/MMAC1 tumor suppressor induces cell death that is rescued by the AKT/protein kinase B oncogene. Cancer Research, 58, 5667-5672.

92. Di Cristofano, A., Pesce, B., Cordon-Cardo, C., \& Pandolfi, P. P. (1998). Pten is essential for embryonic development and tumour suppression. Nature Genetics, 19, 348-355.

93. Podsypanina, K., Ellenson, L. H., Nemes, A., Gu, J., Tamura, M., Yamada, K. M., et al. (1999). Mutation of Pten/Mmac1 in mice causes neoplasia in multiple organ systems. Proceedings of the National Academy of Sciences of the United States of America, 96, 1563-1568.

94. Suzuki, A., de la Pompa, J. L., Stambolic, V., Elia, A. J., Sasaki, T., del Barco Barrantes, I., et al. (1998). High cancer susceptibility and embryonic lethality associated with mutation of the PTEN tumor suppressor gene in mice. Current Biology, 8, 1169-1178.

95. Yoo, L. I., Liu, D. W., Le Vu, S., Bronson, R. T., Wu, H., \& Yuan, J. (2006). Pten deficiency activates distinct downstream signaling pathways in a tissue-specific manner. Cancer Research, 66, 1929-1939.

96. Ma, X., Ziel-van der Made, A. C., Autar, B., van der Korput, H. A., Vermeij, M., van Duijn, P., et al. (2005). Targeted biallelic inactivation of Pten in the mouse prostate leads to prostate cancer accompanied by increased epithelial cell proliferation but not by reduced apoptosis. Cancer Research, 65, 5730-5739.

97. Leslie, N. R., \& Downes, C. P. (2004). PTEN function: How normal cells control it and tumour cells lose it. Biochemical Journal, 382, 1-11.
98. Gustafson, S., Zbuk, K. M., Scacheri, C., \& Eng, C. (2007). Cowden syndrome. Seminars in Oncology, 34, 428-434.

99. Tsuruta, H., Kishimoto, H., Sasaki, T., Horie, Y., Natsui, M., Shibata, Y., et al. (2006). Hyperplasia and carcinomas in Ptendeficient mice and reduced PTEN protein in human bladder cancer patients. Cancer Research, 66, 8389-8396.

100. Puzio-Kuter, A. M., Castillo-Martin, M., Kinkade, C. W., Wang, X., Shen, T. H., Matos, T., et al. (2009). Inactivation of p53 and Pten promotes invasive bladder cancer. Genes and Development, 23, 675-680.

101. Aveyard, J. S., Skilleter, A., Habuchi, T., \& Knowles, M. A. (1999). Somatic mutation of PTEN in bladder carcinoma. British Journal of Cancer, 80, 904-908.

102. Kagan, J., Liu, J., Stein, J. D., Wagner, S. S., Babkowski, R., Grossman, B. H., et al. (1998). Cluster of allele losses within a $2.5 \mathrm{cM}$ region of chromosome 10 in high-grade invasive bladder cancer. Oncogene, 16, 909-913.

103. Cappellen, D., Diez, G., de Medina, S., Chopin, D., Thiery, J. P., \& Radvanyi, F. (1997). Frequent loss of heterozygosity on chromosome 10q in muscle-invasive transitional cell carcinomas of the bladder. Oncogene, 14, 3059-3066.

104. Hurst, C. D., Fiegler, H., Carr, P., Williams, S., Carter, N. P., \& Knowles, M. A. (2004). High-resolution analysis of genomic copy number alterations in bladder cancer by microarray-based comparative genomic hybridization. Oncogene, 23, 2250-2263.

105. Wang, D. S., Rieger-Christ, K., Latini, J. M., Moinzadeh, A., Stoffel, J., Pezza, J. A., et al. (2000). Molecular analysis of PTEN and MXI1 in primary bladder carcinoma. International Journal of Cancer, 88, 620-625.

106. Liu, J., Babaian, D. C., Liebert, M., Steck, P. A., \& Kagan, J. (2000). Inactivation of MMAC1 in bladder transitional-cell carcinoma cell lines and specimens. Molecular Carcinogenesis, 29, 143-150.

107. Cairns, P., Evron, E., Okami, K., Halachmi, N., Esteller, M., Herman, J. G., et al. (1998). Point mutation and homozygous deletion of PTEN/MMAC1 in primary bladder cancers. Oncogene, 16, 3215-3218.

108. Pagliaro, L. C., Keyhani, A., Williams, D., Woods, D., Liu, B., Perrotte, P., et al. (2003). Repeated intravesical instillations of an adenoviral vector in patients with locally advanced bladder cancer: a phase I study of p53 gene therapy. Journal of Clinical Oncology, 21, 2247-2253.

109. Zhang, X., Multani, A. S., Zhou, J. H., Shay, J. W., McConkey, D., Dong, L., et al. (2003). Adenoviral-mediated retinoblastoma 94 produces rapid telomere erosion, chromosomal crisis, and caspase-dependent apoptosis in bladder cancer and immortalized human urothelial cells but not in normal urothelial cells. Cancer Research, 63, 760-765. 